\title{
SEISMICITY RATE CHANGES IN ASSOCIATION WITH TIME DEPENDENT STRESS TRANSFER IN THE REGION OF NORTHERN AEGEAN SEA, GREECE
}

\author{
Leptokaropoulos K. M. ${ }^{1}$, Papadimitriou E. E. ${ }^{1}$, Orlecka-Sikora B. ${ }^{2}$ \\ and Karakostas V. G. ${ }^{1}$ \\ ${ }^{1}$ Geophysics Department, School of Geology, Aristotle University of Thessaloniki, GR54124 Thessaloniki, \\ kleptoka@geo.auth.gr,ritsa@geo.auth.gr,vkarak@geo.auth.gr \\ ${ }^{2}$ Seismology and Physics of the Earth's Interior, Institute of Geophysics, Polish Academy of Sciences, War- \\ saw,Poland,orlecka@igf.edu.pl
}

\begin{abstract}
The region of northern Aegean has suffered several strong earthquakes since the beginning of the $20^{\text {th }}$ century, causing extensive damage and loss of lives. For the seismic hazard assessment in the area, several studies have been accomplished, among them being the ones dealing with the Coulomb stress changes due to the seismic slip caused by major earthquakes, in addition with the constant tectonic loading on the major regional faults. The aim of the present study is to evaluate if seismicity rate changes from 1964 to 2008 are associated with changes in the stress field. For this purpose the stronger events $\left(M_{w} \geq 5.8\right)$ that occurred in this period were considered and their contribution to the stress field evolution was investigated by calculations performed just before and after their occurrence. This influence was then examined in connection with the occurrence rate of small events $\left(M_{w}\right.$ 23.8) for the respective time intervals. After defining the probability density function (PDF) of the small events distribution, a rate/state model was used to correlate static stress changes with seismicity rate and to compare the observed with the expected seismicity rate for each time period.
\end{abstract}

Key words: Coulomb stress, rate/state model, seismicity rates, North Aegean (Greece).

\section{Introduction}

The propagation of the North Anatolian fault to the west, sustains the existence of strike slip faults, most of them dextral, along the North Aegean Trough and the surrounding area. The back-arc extension of the Aegean due to the subduction of the Eastern Mediterranean oceanic plate under the Eurasian, is the second but most prominent dominant effect in the region. Superposition of these two deformation fields, yields an extension increase in the back arc region, leaving almost no significant contraction and reverse faulting in the Aegean. The region exhibits the highest deformation rates and seismicity, moving rapidly towards the SW, due to the combined effect of Anatolia westward motion and subduction rollback (Armijo et al., 2003; Flerit et al., 2004; Papazachos et al., 2006).

Frequent strong earthquakes in the study area are known from both instrumental and historical data. Since 1964, 11 strong earthquakes $(M \geq 5.8)$ occurred in the study area with eight of them being associated with dextral strike slip faulting, two with oblique normal faulting and one with sinistral strike slip fault. As it is shown in Fig. 1, most of these earthquakes are associated with the regional 

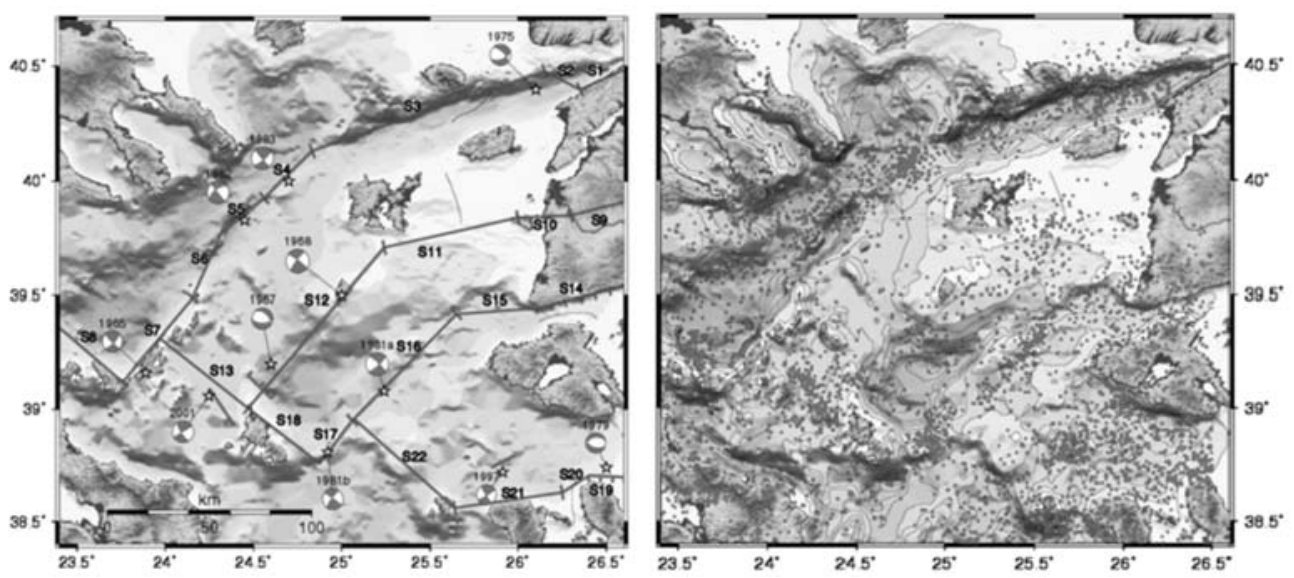

Fig. 1: Morphological map of the region: Gray lines represent the major faults with their code names while red lines show the fault segments that have been ruptured since 1964, giving $M \geq 5.8$ earthquakes. Stars denote the epicenters of these events. The fault plane solutions and the year they occurred are also noted (left). M $\geq 3.8$ seismicity for the period $1964-2008$ is marked with red dots (right).

major faults. Similar is the distribution of seismicity with $\mathrm{M} \geq 3.8$, which is mostly concentrated along the North Aegean Trough (NAT) and in its sub-parallel branches whereas in the south-eastern part the seismicity is more diffused.

The objective of this work is the qualitative and quantitative study of the correlation between the observed seismicity rate at the interevent periods and the expected one, as it is predicted by a model which associates seismicity rate changes with changes in the stress field. Results also depend strongly on the previous (background) seismicity rate, and on the choice of the selected model parameters, such as the apparent friction coefficient, constitutive fault parameter, aftershock duration and distribution of secular tectonic stressing rate. Regions with high seismicity rates are marked, and it is illustrated why some areas appear to be almost aseismic. Finally, estimation is attempted of the regions where seismicity rate is supposed to be high, meaning that they may accommodate a major earthquake in the future. As a conclusion, the seismic hazard assessment seems to be time-depended, and therefore a more accurate determination is necessary in order to avoid or diminish the destructive consequences of an imminent earthquake.

\section{Data}

Most of the fault segments are submarine, and therefore definition of their geometrical and kinematic properties, directly from geological observations is extremely difficult. In this case data is extracted by indirect means. The boundaries and the lengths, $\mathrm{L}$, of the fault segments were determined on the basis of the submarine and continental morphology, seismicity distribution of the last 45 years, aftershock distribution of the stronger events and the reliable available fault plane solutions (Figure 1). Fault plane solutions also provide information on the mean dip and rake of each fault segment. The along strike and downdip components of the slip vector were computed in terms of the geometry of each segment. Fault width, w, was set to: 
Table 1. Source parameters of the 11 earthquakes with $M \geq 5.8$ modeled for coseismic Coulomb static stress changes calculations.

\begin{tabular}{|c|c|c|c|c|c|c|c|}
\hline Year & Date & $\mathbf{M w}$ & $\mathbf{M}_{\mathbf{0}}(\mathbf{d y n} \cdot \mathbf{c m})$ & $\boldsymbol{\phi}$ & $\boldsymbol{\delta}$ & $\boldsymbol{\lambda}$ & Reference \\
\hline 1965 & $9 \mathrm{Mar}$ & 6.1 & $1.47 \cdot 10^{25}$ & 44 & 75 & 175 & Taymaz et al., (1991) \\
\hline 1967 & 4 Mar & 6.3 & $2.43 \cdot 10^{25}$ & 313 & 43 & -56 & Taymaz et al., (1991) \\
\hline 1968 & $19 \mathrm{Feb}$ & 7.0 & $34.5 \cdot 10^{25}$ & 216 & 81 & 173 & Kiratzi et al., (1991) \\
\hline 1975 & $27 \mathrm{Mar}$ & 6.2 & $2.0 \cdot 10^{25}$ & 68 & 55 & -145 & Taymaz et al., (1991) \\
\hline 1979 & $14 \mathrm{June}$ & 5.9 & $0.67 \cdot 10^{25}$ & 262 & 55 & -108 & Taymaz et al., (1991) \\
\hline 1981 & $19 \mathrm{Dec}$ & 6.8 & $22.4 \cdot 10^{25}$ & 47 & 77 & -167 & Kiratzi et al., (1991) \\
\hline 1981 & 27 Dec & 6.3 & $3.82 \cdot 10^{25}$ & 216 & 79 & 175 & Taymaz et al., (1991) \\
\hline 1982 & $18 \mathrm{Jan}$ & 6.6 & $7.32 \cdot 10^{25}$ & 233 & 62 & -177 & Taymaz et al., (1991) \\
\hline 1983 & 6 Aug & 6.6 & $12.1 \cdot 10^{25}$ & 50 & 76 & 177 & Kiratzi et al., (1991) \\
\hline 1997 & 14 Nov & 5.8 & $0.404 \cdot 10^{25}$ & 58 & 83 & 175 & Louvari, (2000) \\
\hline 2001 & 26 Jul & 6.4 & $5.61 \cdot 10^{25}$ & 148 & 76 & -1 & GCMT \\
\hline
\end{tabular}

where h, the width of the seismogenic layer. In this case, seismogenic layer lies between $3-15 \mathrm{~km}$, as it comes from the determination of focal depths of the larger events (Papazachos et al. 2008), and from studies of aftershock sequences with accurate depth determinations. Information on the source parameters of the 11 main shocks included in the model and for which fault plane solutions obtained from body waveform inversion is given on Table 1 .

Smaller magnitude seismicity data were taken from the re-located catalog (Papazachos et al., 2008), which provides more reliable information regarding focal parameters. The catalog contains more than 15,000 events occurred in the region of interest for the time interval from 1964 to May 2008.

\section{Method}

The evaluation of seismicity rate changes in terms of Coulomb static stress changes, is performed on the basis of a rate/state model, modified from Dieterich (1994). Seismicity rate, R, is assumed to be a function of secular stressing rate, . Given a background reference seismicity rate, $\mathbf{r}$, the expected seismicity rate, $R$, is expressed as:

where, $-\mathrm{A}$ is a fault constitutive parameter, $\sigma$ is the total normal stress, $\mathrm{t}_{\mathrm{a}}$, is the characteristic relaxation time for the perturbation of earthquake rate (aftershock duration), $t$, is a given time step for seismicity rate calculation and $\triangle \mathrm{CFF}$ is the coseismic Coulomb stress changes, given by:

where $\Delta \tau$, is shear stress change, $\Delta \sigma_{\mathrm{n}}$, is the normal stress change and $\mu^{\prime}$, the apparent coefficient of friction, including pore pressure effects. 
Background and observed seismicity rate at any interevent time interval is translated into earthquake probability with the use of a probability density function (PDF). This function determines the background seismicity rate at the center of each cell of a normal grid superimposed on the study area and these values are considered constant in time as the same is considered for the secular tectonic stressing rate. Probability is calculated with the application of a PDF proposed by Silverman (1986) and has the form:

where $\mathrm{X}_{\mathrm{i}}, \mathrm{Y}_{\mathrm{i}}$, are the epicentral coordinates of earthquakes (longitude, $\lambda$ and latitude, $\phi$, respectively), $\mathrm{x}, \mathrm{y}$, are the coordinates of the centers of the bins, on which the value of PDF is going to be estimated, $\mathrm{n}$, is the number of the events and $\mathrm{h}$, is the smoothing parameter (or window width), having the same units with $\mathrm{X}_{\mathrm{i}}, \mathrm{Y}_{\mathrm{i}}, \mathrm{x}, \mathrm{y}$. Finally from the fundamental equation of the probability theory $\Rightarrow \mathrm{n}=\mathrm{P} \cdot \mathrm{N}$, the seismicity rate is estimated for the given time period, $\Delta \mathrm{t}$ as follows:

$$
\mathrm{R}=\mathrm{n} / \Delta \mathrm{t}
$$

This rate, corresponds to the real seismicity rate of the given time period and is compared with the value of expected seismicity rate for the respective time period. Note that the region has been divided into a grid of $60 \times 60=3600$ rectangular cells of $5 \mathrm{~km}$ side. Values of model parameters are estimated in the center of each cell.

\section{Estimation of Model Parameters}

The parameters that are needed to be calculated for the seismicity rate determination are the Coulomb Stress changes $(\triangle \mathrm{CFF})$, due to the coseismic slip of the major $(M \geq 5.8)$ events, the background seismicity rate, $r$, the values of stressing rate , and its distribution along the major faults of the region as well as the aftershocks duration, $\mathrm{t}_{\mathrm{a}}$.

\subsection{Coulomb stress changes calculations}

Static stress changes are considered to be associated with the coseismic slips of the 11 stronger $(M \geq 5.8)$ events that occurred in the study area. Calculations were performed for the whole area, although coseismic slip alters the stress state in a limited area, depending upon the magnitude of the modeled event. $\triangle \mathrm{CFF}$ is calculated from (5) with $\mu^{\prime}$ set to 0.4 (Stein et al., 1997; Nalbant et al., 1998). Shear modulus G, is assumed to be $33 \mathrm{GPa}$ and Poisson ratio 0.25 (Papadimitriou \& Sykes, 2001). The width of seismogenic layer, $\mathbf{h}$ in the region consider to extend down to $15 \mathrm{~km}$ and calculations were done at the depth of $8 \mathrm{~km}$. Fault plane solutions (Table 1) provide fault parameters and $\triangle \mathrm{CFF}$ are calculated in respect to the fault plane that caused the stress perturbation. Components of slip, u, in strike, SS, and dip, DS, directions were estimated using the value of seismic moment, $\mathrm{M}_{\mathrm{o}}$, considering the rake angle:

$$
\mathrm{M}_{\mathrm{o}}=\mathrm{GuLw}
$$

where $\mathrm{G}$, is the shear modulus, $\mathrm{L}$, is the fault length estimated from aftershock distribution along the 
fault segments and scaling laws (Wells \& Coppersmith, 1994; Papazachos et al., 2004) and fault width, w, is estimated using (1).

\subsection{Estimating the Stressing Rate}

The determination of the stressing rate on the major faults of the study area is necessary for the expected seismicity rate estimation. It is assumed that the stressing rate is time independent and its spatial distribution is non uniform, but it is concentrated in specific zones of weakness, which define the major regional faults (Scholz, 1990). The values of stressing rate are used to determine the state variable $\gamma$, applied in the rate/state model, for each time step. In the present study, the slip rates on the major faults as they were defined from geodetic data (Flerit et al., 2004; Reilinger et al., 2006) were used in order to determine the stressing rates onto them. Geometrical characteristic and slip rates of these fault were estimated as described in section 2. In calculations, only $60 \%$ of the slip rate value was considered for accounting the seismic part of the secular tectonic motion. Different values for seismic coupling along the NAF and its surroundings have been proposed and they vary between 20-75\% (Ward, 1998; Ayhan et al., 2001; Bird \& Kagan, 2004), but most of them conclude to a value close to $60 \%$.

The estimated values of the stressing rate at the center of each fault segment vary from 0.0025 to $0.086 \mathrm{bar} / \mathrm{yr}$ and they are assigned for narrow stripes of $5 \mathrm{~km}$ width on either side at the fault trace of each segment. A percentage of stressing rate value is considered for each cell at these zones. For the rest of the cells, a very low value of stressing rate was set in order to avoid singularity computations. Thus every cell has two components of Coulomb stress change, one due to coseismic slip and one because of tectonic loading. These values will be used in the rate/state model in order to calculate the seismicity rate changes. A mean value of 0.0275 bar/year yielding from Gaussian fitting of data was later used as simplification to test results come from different approaches. This value appears to be in agreement with the ones given by Parsons et al. (2004) for the Sea of Marmara. Considering also that the slip rates are higher at the eastern part of NAF, this value is also consistent with the ones proposed by Straub et al. (1997) and Stein et al. (1997) for the NAF segments.

\subsection{Estimating the background seismicity rate}

Seismicity rate changes in a region are determined with regard to a reference seismicity rate. This reference rate must be free of dependent events that are aftershocks, triggered by a main shock. Habermann \& Wyss (1984) defined the background seismicity rate as the rate of occurrence of events which one considers normal for some region. This happens when the only influence in the region is the tectonic loading and there is no stress perturbation because of other earthquakes. Therefore the recognition and removal of such dependent events is very important for the procedure in order to estimate and interpret properly the changes of the seismicity rate.

The catalog used for this procedure must be complete over a minimum magnitude, $\mathbf{M}_{\mathrm{c}}$, and also not to include dependent events (aftershocks). Determination of $\mathrm{M}_{\mathrm{c}}$ is very important when seismicity rate is studied because only the events with $\mathrm{M} \geq \mathrm{M}_{\mathrm{c}}$ must be included to determine accurately real and modeled seismicity rates. $\mathrm{M}_{\mathrm{c}}$ was calculated for the entire time period as well as for the interval 19812008. In both cases it was found roughly equal to 3.8. That leaves less than 5,000 events at the complete and homogenous catalog considering the 44 years period.

The next step is the identification and removal of the aftershocks. In seismicity studies two main clusters of earthquakes are recognized. Those whose rate decays with time such as aftershocks and swarms 


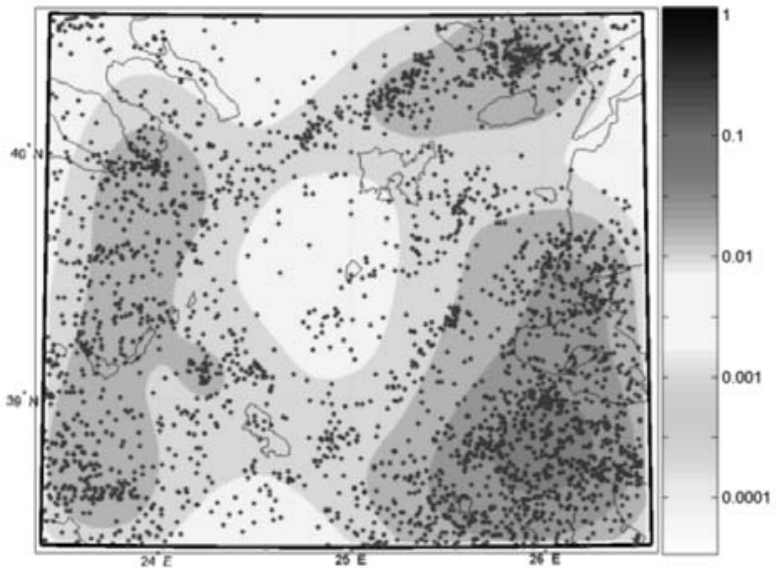

Fig. 2: Background seismicity rate estimated from PDF (equation 4). Smoothing parameter was found by equation 8 , equal to 0.22 . Red colors indicate higher rates. Blue dots represent epicenters of the earthquakes $(\mathrm{M} \geq 3.8)$ occurred during the period 1964-2008, with aftershocks being excluded.

and those whose rate and spatial distribution is time independent at a specific area. The declustering procedure in this study was based on Reasenberg's (1985) algorithm. Aftershock populations are identified by modeling an interaction zone about each earthquake in the catalog. These zones are constructed with one spatial and one temporal parameter. Spatial limits of the zone are defined by the estimate of stress redistribution in the vicinity of each earthquake (magnitude-dependent), whereas temporal extend of the zone is determined with an Omori's law based probabilistic model. Every event that occurs within this interaction zone of a prior event is considered statistically dependent on it (aftershock). After declustering, the final data set contains 2800 events which represent the background seismicity of the region, which is translated in terms of probabilities with use of PDF.

\subsection{Choice of window width}

It is clear from (9), that the value of probability is a function of the smoothing parameter, h. It represents the expanse of the area which is being influenced by each value of P1. Many methods have been proposed for a proper h value estimate (Silverman, 1978; Hall et al., 1991; Sain et al., 1994). In general, high values of the window width represent better systematic variation, while smaller values make random fluctuation clearer. In the present study the Silverman's (1986) formulation was applied:

where $\sigma^{2}=0.5\left(s_{x x}+s_{y y}\right)$ and $s_{x x}$ and $s_{y y}$ are sample variances of $X_{i}$ and $Y_{i}$ respectively and $\mathrm{K}$ the number of events included in the period of interest. The background seismicity rate for the study period (1964-2008) is shown in Fig. 2. Rate/state formulation as it was discussed, gives the values of expected seismicity rate after a main shock. These values are compared with the real seismicity rate for this period as it yields from PDF equations. Qualitative fitting can be estimated by comparison of the patterns of observed and expected seismicity and the locations of the events that occurred during the respective periods. Quantitative comparison can be done by calculation of the correlation coefficient between the observed and expected values of seismicity rate. Time windows for calculations correspond to interevent periods except from December 1981 to January 1982 (3 main shocks), where time intervals are too short and catalogue is too poor to provide reliable results. 
Table 2. Correlation coefficients between expected and observed seismicity rate at 7 time windows according to 13 different approaches discussed in the text. Last column shows the mean value of each model, while last line shows the mean value of all models for each time interval. Bold values stand for the highest value for each time period. Total average is $0.5581 \pm 0.037$. Model 'c' results were not included in this average estimate. Correlation Coefficient was computed by application of the formula:

where $\mathrm{x}, \mathrm{y}$, the values of the observed and expected seismicity rate respectively and $\mathrm{n}$, the number of cells.

\begin{tabular}{|c|c|c|c|c|c|c|c|c|}
\hline & $67-68$ & $68-75$ & $75-79$ & $79-81$ & $83-97$ & $97-01$ & $01-08$ & average \\
\hline a1 & $\mathbf{0 . 5 8 1 1}$ & 0.4778 & 0.2566 & 0.5479 & 0.7153 & 0.7197 & 0.7519 & 0.5786 \\
\hline a2 & 0.4788 & 0.5142 & 0.2993 & 0.5221 & 0.7284 & 0.7287 & 0.7608 & 0.5760 \\
\hline a3 & 0.3601 & $\mathbf{0 . 5 6 8 4}$ & 0.2944 & 0.5019 & 0.7065 & 0.7023 & 0.7842 & 0.5597 \\
\hline a4 & 0.5371 & 0.4693 & 0.2976 & 0.5355 & 0.7022 & 0.7041 & 0.7327 & 0.5684 \\
\hline b1 & 0.5688 & 0.4441 & 0.2401 & 0.5361 & 0.6868 & 0.7088 & 0.7254 & 0.5586 \\
\hline b2 & 0.4665 & 0.472 & 0.2848 & 0.51 & 0.6921 & 0.7084 & 0.7281 & 0.5517 \\
\hline b3 & 0.3561 & 0.5298 & 0.2768 & 0.4881 & 0.6767 & 0.6885 & 0.7640 & 0.5400 \\
\hline b4 & 0.5189 & 0.4314 & 0.2798 & 0.5246 & 0.6629 & 0.6833 & 0.6955 & 0.5423 \\
\hline c* & 0.1919 & 0.1 & 0.002 & 0.255 & 0.35 & 0.4316 & 0.22 & 0.2215 \\
\hline d & 0.3537 & 0.517 & $\mathbf{0 . 3 2 3 8}$ & 0.471 & 0.6833 & 0.5571 & 0.5987 & 0.5007 \\
\hline e1 & 0.4469 & 0.4097 & 0.2623 & 0.4357 & 0.6516 & 0.6321 & 0.6277 & 0.4951 \\
\hline e2 & 0.4882 & 0.5467 & 0.3162 & 0.5435 & 0.7655 & 0.7747 & 0.8175 & 0.6075 \\
\hline e3 & 0.4910 & 0.5553 & 0.3223 & $\mathbf{0 . 5 6 3 0}$ & $\mathbf{0 . 7 7 6 3}$ & $\mathbf{0 . 7 8 6 9}$ & $\mathbf{0 . 8 3 4 2}$ & 0.6184 \\
\hline average & 0.4706 & 0.4946 & 0.2878 & 0.5149 & 0.7040 & 0.6996 & 0.7351 & \\
\hline
\end{tabular}

\section{Results}

Calculations of the expected seismicity rate and their correlation with real seismicity rates were done considering 13 different assumptions, shown in Table 2, in order to test the influence of the variance of model parameters on the results. Parameters examined are the window width, $h$, the aftershock duration, $\mathrm{t}_{\mathrm{a}}$ and the value and distribution of the secular tectonic stressing rate, . Cluster ' $\mathrm{a}$ ' models, assume spatially uniform stressing rate, $=0.0275 \mathrm{bar} / \mathrm{yr}$ and aftershock duration $\mathrm{t}_{\mathrm{a}}=25 \mathrm{yr}$, yielding a constant value of $A \sigma=0.6875$ bar. The window width at each period was selected according to equation (8) for ' $a 1$ ' and was set to $0.22,0.12$ and 0.3 in a2, a3 and a4, respectively. Cluster ' $b$ ' models, have the same approach with cluster ' $a$ ' except for the aftershock duration, which was set to $15 \mathrm{yr}$. Results are better considering $\mathrm{h}=0.22$, and $\mathrm{t}_{\mathrm{a}}=25 \mathrm{yr}$ and therefore these values were used in the other models. Model 'c', assumes spatially varying stressing rate as it was discussed in 4.2, resulting to an A $\sigma$ value varying from 0.01 to 3.65 bars. Model 'd', also assumes spatially varying stressing rate, but A $\sigma$ was set to be uniform and equal to 0.4 bars. Cluster 'e' models, assume spatially uniform stressing rate value equal to $0.01,0.05$ and $0.064 \mathrm{bar} / \mathrm{yr}$, respectively. 

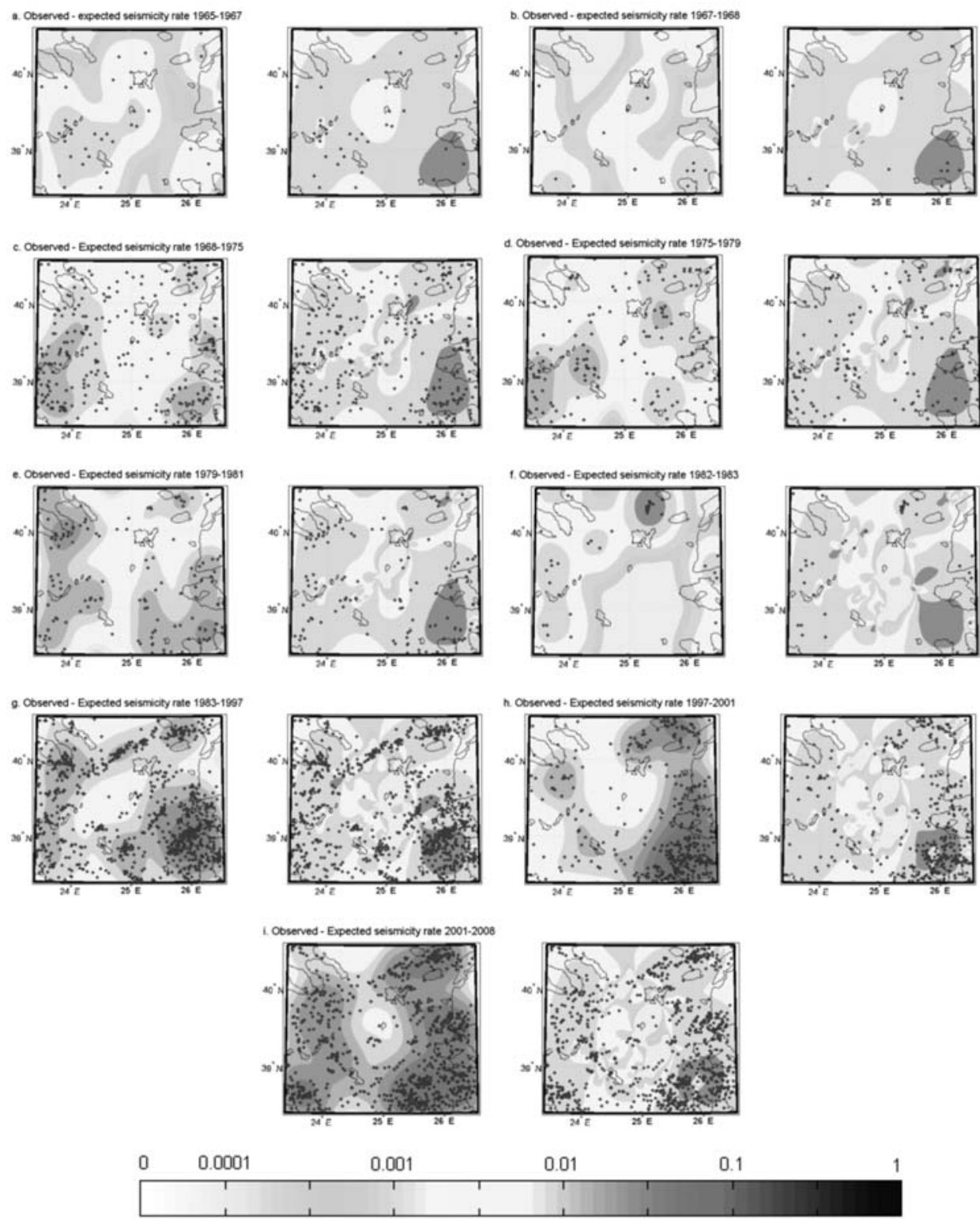

Fig. 3: Comparison of observed and expected seismicity rates in the study area with $\mathrm{t}_{\mathrm{a}}=25 \mathrm{yrs}, \quad=0.0275 \mathrm{bar} / \mathrm{yr}$ and $\mathrm{h}=0.22$. Warm colors represent high seismicity rate, cold colors stand for low rates. Blue dots, represent the epicentral location of earthquakes occurred in the interevent time of each case. Qualitative and quantitative correlation is better in the three last figures $(3 \mathrm{~g}, 3 \mathrm{~h}, 3 \mathrm{i}$ ) corresponding to seismicity rates after 1983.

Patterns of observed - expected seismicity, extracted from model 'a1' are shown in Fig. 3. As it is shown in Table 2 and Fig. 3, time periods after 1983 produce better correlation between observed and expected values of seismicity rate. This happens because of the better quality of the catalog after 1983, the longer interevent times, which provide larger sample and possible stress perturbation 
in the region by earthquakes occurred before 1964 and therefore they are not included in modeling. Another evidence supporting this aspect is that the time periods 1965-1967 and 1982-1983, provide almost zero correlation irrespective to the model (they are not included in Table 2). Very high values of expected seismicity rate, yielding from modeling, were set to the highest value of background seismicity rate.

\section{Discussion and Conclusions}

Seismicity rate changes in the region of North Aegean, Greece, from 1964 to 2008 were studied, in association with Coulomb stress changes due to seismic slip caused by the 11 stronger events $\left(\mathrm{M}_{\mathrm{w}}\right.$ $\geq 5.8$ ) that occurred in this time interval. This influence was then examined in connection with the occurrence rate of small events $\left(\mathrm{M}_{\mathrm{w}} \geq 3.8\right)$ for the respective time intervals. Seismicity was translated into earthquake probability for events with $\mathrm{M}_{\mathrm{w}} \geq 3.8$ and a rate/state model was used to associate static stress changes with seismicity rate and to compare and correlate the observed with the expected seismicity rate for each time period.

The mean correlation coefficient come from application of all models, except 'c', is $0.5581 \pm 0.037$. It means the model can explain over half of seismicity distribution independently on the approach. Mean value is also very high during the 3 latest time intervals, approaching $72 \%$. Better results arise considering aftershock duration to be 25 rather than 15 or 5 years. In the last case the mean correlation coefficient equals to 0.48 , much lower than the average computed by the other models. Choice of a window width equal to 0.22 , not only provides good correlation coefficient, but also better patterns for qualitative comparison. Very high values of $h(>0.3)$, as applied in early periods on models 'a1' and 'b1', result to an oversmoothed pattern that does not reflect real seismicity distribution. However the choice of $h$ and $t_{a}$, slightly affects the results.

Assuming non-uniform stressing rate and A $\sigma$ (model ' $c$ '), the correlation is very low. This happens because of the lack of knowledge regarding the uncertainties concerning the spatial influence of the stressing rate assigned in limited areas, in combination with epicentral location uncertainties and

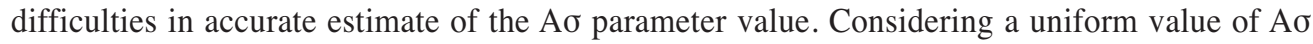
(model ' $\mathrm{d}$ '), the correlation is also lower, but comparable with the ones obtained from the other models. Variation of uniform stressing rate value , also affects the results. The higher the value of stressing rate applied, the better the yielding correlation. Especially in 'e3' model ( $=0.064$ bar/yr), the higher the correlation coefficient exceeds $83 \%$ (for 2001-2008 interval) with an average near $62 \%$. This fact shows that influence of tectonic loading is very important, and therefore stressing rate has to be more accurately estimated for future applications.

The results obtained in this study demonstrate that the methodology applied is efficient for seismic hazard assessment. The number of events with magnitude larger than or equal to 3.8 can be estimated for any time period, given a magnitude-frequency relation. For the stronger events, which are rare, the occurrence probability can be estimated instead. For a stationary Poisson process the value of this probability, $\mathrm{P}$, is $\mathrm{P}=1-\exp (\mathrm{N})$, where, $\mathrm{N}$, is the number of expected events in a time interval and area of interest (Toda \& Stein, 2003).

As shown in Fig. 3, the area with the highest expected value of seismicity rate is the south-eastern part of the region. A distinct shadow zone appears to occupy the central part of the study region, yielding from high negative $\triangle \mathrm{CFF}$ values by the stronger earthquakes occurred there. Characteristic pattern of the 1968 M7.0 event is present, although 40 years have already passed. Earthquake absence is obvious in this region, especially after 1990 . A mean correlation coefficient of $73.5 \%$ for 
the time interval 2001-2008, confirms that the model becomes more accurate when data are more sufficient and influence of former events, not included in the stress calculations has disappeared. Nevertheless, modeling and parameter values estimation can be improved for future applications, for a more reliable time-dependent seismic hazard assessment to be achieved.

\section{Acknowledgments}

The stress tensors were calculated using the DIS3D code of S. Dunbar, which was later improved by Erikson (1986) and the expressions of G. Converse. The GMT system (Wessel and Smith, 1998) was used to plot some of the figures. The first of the author greatly benefited from discussions and software assistance with Stan Lasocki and Janusz Mirek during his stay in AGH University. Geophysics Department, AUTH, contribution number 751.

\section{References}

Armijo, R., Flerit, F., King, G. and Meyer, B., 2003. Linear elastic fracture mechanics explains the past and present evolution of the Aegean, Earth Planet. Sci. Lett. 217, 85-95.

Ayhan, M. E., Bürgmann, R., McCluskey, S., Lenk, O., Aktug, B., Herece, E. and Reilinger, R. E., 2001. Kinematics of the $\mathrm{M}_{\mathrm{w}}=7.2,12$ November 1999, Dúzce, Turkey earthquake, Geophys. Res. Lett., 28, $367-370$.

Benetatos, C., Z. Roumelioti, A. Kiratzi, and N. Melis (2002), Source parameters of the M 6.5 Skyros Island (North Aegean Sea) earthquake of July 26, 2001, Ann. Geophys., 45, 513-526.

Bird, P. and Kagan, Y., 2004. Plate-tectonic analysis of shallow seismicity: apparent boundary width, beta, corner magnitude, coupled lithosphere thickness and coupling in seven tectonic settings, Bull. Seismol. Soc. Am., 94, 2380-2399.

Dieterich, J. H., 1994. A constitutive law for rate of earthquake production and its application to earthquake clustering, J. Geophys. Res., 99, 2601-2618.

Dieterich, J. H., and Kilgore, B., 1996. Implications of fault constitutive properties for earthquake prediction, Proc. Natl. Acad. Sci., 93, 3787-3794.

Erikson, L., 1986. User's manual for DIS3D: A three-dimensional dislocation program with applications to faulting in the Earth. Masters Thesis, Stanford Univ., Stanford, Calif., 167 pp.

Flerit F., Armijo, R., King, G. and Bertrand, M., 2004. The mechanical interaction between the propagating North Anatolian Fault and the back-arc extension in the Aegean, Earth Planet. Sci. Lett., 224, 347362 .

Habermann, R. E. and Wyss, M., 1984. Background seismicity rates and precursory seismic quiescence: Imperial Valley, California, Bull. Seismol. Soc. Am., 74, 1743-1755.

Hall, P., Sheather, S. J., Jones, M. C., and Marron, J. S., 1991. On optimal data-based bandwidth selection in kernel density D. estimation, Biometrika, 78, 263-269.

Kiratzi, A. A., Wagner, G. S., and Langston, C. A., 1991. Source parameters of some large earthquakes in Northern Aegean determined by body waveform inversion, Pure Appl. Geophys., 135, 515-527.

Louvari, E., 2000. A detailed seismotectonic study in the Aegean Sea and the surrounding area with emphasis on the information obtained from microearthquakes. $\mathrm{PhD}$ Thesis, Aristotle Univ., Thessaloniki, Greece, pp. 373.

Nalbant, S. S., Hubert, A. and King, G. C. P., 1998. Stress coupling between earthquakes in northwest Turkey and the north Aegean Sea, J. Geophys. Res., 103, 24,469-24.486.

Papadimitriou, E. E. and Sykes, L.R., 2001. Evolution of the stress field in the northern Aegean Sea 
(Greece), Geophys. J. Int., 146, 747-759.

Papadopoulos, A., A. Ganas, and A. Plessa (2002), The Skyros earthquake ( $\left.M_{w} 6.5\right)$ of 26 July 2001 and precursory seismicity patterns in the North Aegean Sea, Bull. Seismol. Soc. Am., 92, 3, 1141-1145.

Papazachos, B. C., Scordilis, E. M., Panagiotopoulos, D. G., Papazachos, C. B. and Karakaisis, G. F., 2004. Global relations between seismic fault parameters and moment magnitude of earthquakes, Bull. Geol. Soc. Greece, 36, 1482-1489.

Papazachos, B. C., Karakaisis, C. B., Papazachos, C. B. and Scordilis, E. M., 2006. Perspectives for earthquake prediction in the Mediterranean and contribution of geological observations, Geolog. Soc. London, Spec. Publ., 260, 689-707.

Papazachos, B. C., Comninakis, P. E., Karakaisis, G. F., Karakostas, B. G., Papaioannou, Ch. A., Papazachos, C. B. and Scordilis, E. M., 2008. A catalogue of earthquakes in Greece and surrounding area for the period 550BC-2008. Geophysics Dept., Thessaloniki University, 2008.

Parsons, T., 2004. Recalculated probability of $\mathrm{M} \geq 7$ earthquakes beneath the Sea of Marmara, Turkey, $J$. Geophys. Res., 109, B05304, doi:10.1029/2003JB002667.

Reasenberg, P., 1985. Second order moment of central California Seismicity, 1969-1982, J. Geophys. Res, 90, B7, 5479-5495.

Reilinger, R., et al., 2006. GPS constraints on continental deformation in the Africa-Arabia-Eurasia continental collision zone and implications for the dynamics of plate interactions, J. Geophys. Res., 111, B05411, doi:10.1029/ 2005JB004051.

Sain, S. R., Baggerly, K. A., and Scott, D. W., 1994. Cross-validation of multivariable densities, J. American Stat. Assoc., 89, 807-817.

Scholz, C. H., 1990. The Mechanics of Earthquakes and Faulting, Cambridge University Press, Cambridge, 439, 439pp.

Silverman, B. W., 1978. Choosing the window width when estimating a density, Biometrika, 65, 1-11.

Silverman, B. W., 1986. Density Estimation for Statistic and Data Analysis, Chapman and Hall, London, 9,21pp.

Stein, R. S., Barka, A. A. and Dieterich, J. H., 1997. Progressive failure on the North Anatolian fault since 1939 by earthquake stress triggering, Geophys. J. Int, 128, 594-604.

Straub, C., Kahle, H.-G. and Schindler, C., 1997. GPS and geologic estimates of the tectonic activity in the Marmara sea region, NW Anatolia, J. Geophys. Res., 102, 27,587-27,601.

Taymaz, T., Jackson, J. and McKenzie, D., 1991. Active tectonics of the north and central Aegean sea, Geophys. J. Int., 106, 433-490.

Toda, S. and Stein, R. S., 2003. Toggling of seismicity by the 1997 Kagoshima earthquake couplet: A demonstration of time-dependent stress transfer, J. Geophys. Res., 108, B12, 2567, doi: $10.1029 / 2003 J B 002527$.

Ward, S. N., 1998. On consistency of earthquake moment release and space geodetic strain rates: Europe, Geophys. J. Int., 135, 1011-1018.

Wells, D. L. and Coppersmith, K. J., 1994. New empirical relationships among magnitude, rupture length, rupture width, rupture area and surface displacement, Bull. Seismol. Soc. Am. 84, 974-1002.

Wessel, P. and Smith, W. H. F., 1998. New, improved version of the Generic Mapping Tools Released, EOS Trans. AGU, 79, 579. 